Research Paper

\title{
Effect of laser therapy on expression of angio- and fibrogenic factors, and cytokine concentrations during the healing process of human pressure ulcers
}

\author{
Jakub Taradaj ${ }^{1,2}{ }^{\bowtie}$, Barbara Shay2 ${ }^{2}$, Robert Dymarek ${ }^{3}$, Mirosław Sopel ${ }^{3}$, Karolina Walewicz ${ }^{4}$, Dimitri \\ Beeckman ${ }^{5}$, Lisette Schoonhoven ${ }^{6}$, Amit Gefen7, Joanna Rosińczuk ${ }^{3}$
}

1. Department of Physiotherapy Basics, Academy of Physical Education, 72B Mikolowska St, 40-065 Katowice, Poland

2. College of Rehabilitation Sciences, University of Manitoba, McDermot Av, R106 - 771, Winnipeg, Canada

3. Department of Nervous System Diseases, Wroclaw Medical University, 5 Bartla St, 51-618, Wroclaw, Poland

4. Faculty of Physiotherapy, Public Higher Medical Professional School, 68 Katowicka St, 45-060, Opole, Poland

5. University Centre for Nursing and Midwifery, Department of Public Health, Ghent University, De Pintelaan 1855 K3 B-9000, Ghent, Belgium

6. Faculty of Health Sciences, University of Southampton, University Rd SO17 1BJ, Southampton, United Kingdom

7. Department of Biomedical Engineering, Tel Aviv University, P.O. Box 39040, 6997801, Tel Aviv, Israel

$\square$ Corresponding author: Jakub Taradaj, Department of Physiotherapy Basics, Academy of Physical Education, 72B Mikolowska St, 40-065 Katowice, Poland; College of Rehabilitation Sciences, University of Manitoba, McDermot Av, R106 - 771, Winnipeg, Canada. Email j.taradaj@awf.katowice.pl; Tel.: +48668613945

(C) Ivyspring International Publisher. This is an open access article distributed under the terms of the Creative Commons Attribution (CC BY-NC) license (https://creativecommons.org/licenses/by-nc/4.0/). See http://ivyspring.com/terms for full terms and conditions.

Received: 2018.02.21; Accepted: 2018.05.25; Published: 2018.07.13

\begin{abstract}
Objective: To evaluate the effect of laser irradiation at different wavelengths on the expression of selected growth factors and inflammatory mediators at particular stages of the wound healing process.

Methods: Sixty-seven patients were recruited, treated, and analyzed (group A - $940 \mathrm{nm:} 17$ patients; group B - $808 \mathrm{~nm}$ : 18 patients; group C - $658 \mathrm{~nm}$ : 16 patients; group D - sham therapy: 17 patients). Patients received a basic treatment, including repositioning and mobilization, air pressure mattress and bed support surfaces, wound cleansing and drug therapy. Additionally, patients received laser therapy once a day, 5 times a week for 1 month in use of a semiconductor lasers (GaAlAs) which emitted a continuous radiation emission at separate wavelengths of $940 \mathrm{~nm}$ (group A), $808 \mathrm{~nm}$ (group B) and $658 \mathrm{~nm}$ (group C). In group D (sham therapy), laser therapy was applied in the same manner, but the device was off during each session (only the applicator was switched on to scan pressure ulcers using none coherent red visible light).

Results: The positive changes in the measured serum (IL-2, IL- 6 and TNF- $\alpha$ ) and wound tissue (TNF- $\alpha$, VEGF and TGF $\beta 1$ ) parameters appeared to be connected only with the wavelength of $658 \mathrm{~nm}$. The significant change in pro-inflammatory mediator levels [interleukin 2 (IL-2) with $p=0.008$ and interleukin $6(\mathrm{IL}-6)$ with $p=0.016$ ] was noticed after two weeks of laser therapy. In the other groups, the inflammation was also reduced, but the process was not as marked as in group C. Similarly, in the case of tumor necrosis factor (TNF- $\alpha$ ) concentration, where after two weeks of treatment with irradiation at a wavelength of $658 \mathrm{~nm}$, a rapid suppression was observed $(p=0.001)$, whereas in the other groups, these results were much slower and not as obvious. Interestingly, again in the case of group $C$, the change in TNF- $\alpha$ concentration in wound tissue was most intensive ( $\approx 75 \%$ reduction), whereas the changes in other groups were not as obvious ( $\approx 50 \%$ reduction). After irradiation $(658 \mathrm{~nm})$, the VEGF expression increased significantly within the first two weeks, and then it decreased and maintained a stable level. In contrast, the TGF 1 l activity remained level, but always higher in comparison to other groups

Conclusions: The effective healing of pressure ulcers is connected with laser irradiation at a wavelength of $658 \mathrm{~nm}$. We believe that this effect is related to the inhibition of inflammatory processes in the wound and stimulation of angiogenesis and fibroblast proliferation at this specific radiation (based both on concentration of interleukins and TNF- $\alpha$ serum level and VEGF, TGF $\beta 1$, TNF- $\alpha$ activities in wound biopsies). Laser therapy at wavelengths of 940 and $808 \mathrm{~nm}$ does not significantly affect the above-mentioned repair processes, which explains its low effectiveness in the treatment of pressure ulcers.
\end{abstract}

Key words: pressure ulcers; laser therapy; growth factors; interleukins 


\section{Introduction}

The management of pressure ulcers is an extremely important clinical, social and economic problem [1, 2, 3]. It is upsetting that despite the enormous technological advances in medicine that have taken place over the last decades, there is still unsatisfactory effective, affordable, and versatile method of treatment for every patient with pressure ulcers (without many contraindications and limitations). Therefore, researchers are more inclined to seek new and unconventional methods, sometimes also in the field of physical therapy $[4,5,6,7,8]$.

In recent years, the interest in the application of laser therapy in supporting chronic wound healing has increased $[9,10,11]$. However, the effectiveness and usefulness of this method has not been unequivocally confirmed so far. According to the latest (the next edition is scheduled for 2019) global consensus of three scientific societies dealing with the subject of treatment of pressure ulcers (the European and US National Pressure Ulcer Advisory Panels EPUAP and NPUAP, along with the Pan Pacific Pressure Injury Alliance - PPPIA) entitled "Prevention and Treatment of Pressure Ulcers: Clinical Practice Guideline" [12], recommendations for the use of laser radiation are based only on vague presumptions and ambiguous conclusions arising from case reports (case studies or methodologically weak pilot clinical trials), comments and expert opinions. This is the reason why at this stage, recommendations for laser therapy as a treatment in pressure ulcers are on the lowest level of evidence, according to the Evidence-Based Medicine (EBM).

In 2013, our team published the results of randomized clinical trial [13], which evaluated the efficacy of laser therapy at different wavelengths to treat pressure ulcers. Seventy-two patients with pressure ulcers were allocated to one of four comparison groups, in a single blind trial method with laser therapy at different wavelengths: (group 1) $940 \mathrm{~nm}$; (group 2), $808 \mathrm{~nm}$; (group 3), $658 \mathrm{~nm}$; and (group 4), sham laser therapy. The procedures were performed once a day, 5 days a week for the period of 1 month. The wound healing process measured by digital planimetry was evaluated before physical procedures, immediately after the end of treatment, and 1, 3 months later as a follow-up. The results were relatively surprising, as only irradiations at the wavelength of $658 \mathrm{~nm}$ was found to be more effective than the other three methods and led to rapid and fairly spectacular therapeutic progress in comparison to the control group. Interestingly, the other wavelength of radiation (940 and $808 \mathrm{~nm}$, much more popular in clinical practice than $658 \mathrm{~nm}$ ), did not significantly influence the healing process and did not even show any statistically significant advantage over sham therapy.

The above study results have confirmed the need to conduct a study with the aim to evaluate the mechanisms of healing with laser irradiation in the treatment of pressure ulcers. It seems that the lack of knowledge of the effects of laser therapy on healing processes at the molecular and immunological level (such as the expression of angio- and fibrogenic factors, and cytokine concentrations) significantly hinders the use of this method in clinical practice. Without establishing and understanding the effects of radiation on the wound and healing processes based on basic sciences, it is difficult to substantiate the use of laser irradiation technology in hospital or outpatient settings in patients with pressure ulcers.

The aim of the present study was to evaluate the effect of laser irradiation at different wavelengths 940, 808 and $658 \mathrm{~nm}$ (in reference to previous clinical trials of our team and the publication from 2013, and above all to conduct the same concept and methodology) on the expression of selected growth factors and inflammatory mediators at particular stages of the wound healing process.

\section{Materials and Methods}

\section{Study Design}

The study was performed between April 2015 and October 2017 in two medical centers in accordance with the guidelines of the Declaration of Helsinki and the Principles for Good Clinical Practice, as well as respecting the rights and dignity of the other person. The study was approved by the local Bioethics Committee (file reference number 4/2014). Written informed consent was obtained from all patients. In addition, the study was registered prospectively on the Australian New Zealand Clinical Trial Registry platform (ACTRN12615000366550). This paper has been prepared using the CONSORT 2010 guide for the reporting of parallel group randomized trials (Figure 1), as well as the associated documents for randomized trials of non-pharmacological treatments [14].

\section{Settings and Participants}

The study included patients diagnosed with a chronic wound of pressure ulcer-related etiology. The inclusion criteria were: (1) stage II, III or IV according to the EPUAP/NPUAP classification system for pressure ulcer [12], (2) wound area at least $0.5 \mathrm{~cm}^{2}$ and not more than $50 \mathrm{~cm}^{2}$, (3) duration of the condition between min. 6 to max. 24 months and (4) location of pressure ulcers in the sacrum and pelvis (Figure 2). The exclusion criteria were: (1) a clinically detectable wound infection (critical bacterial colonization 


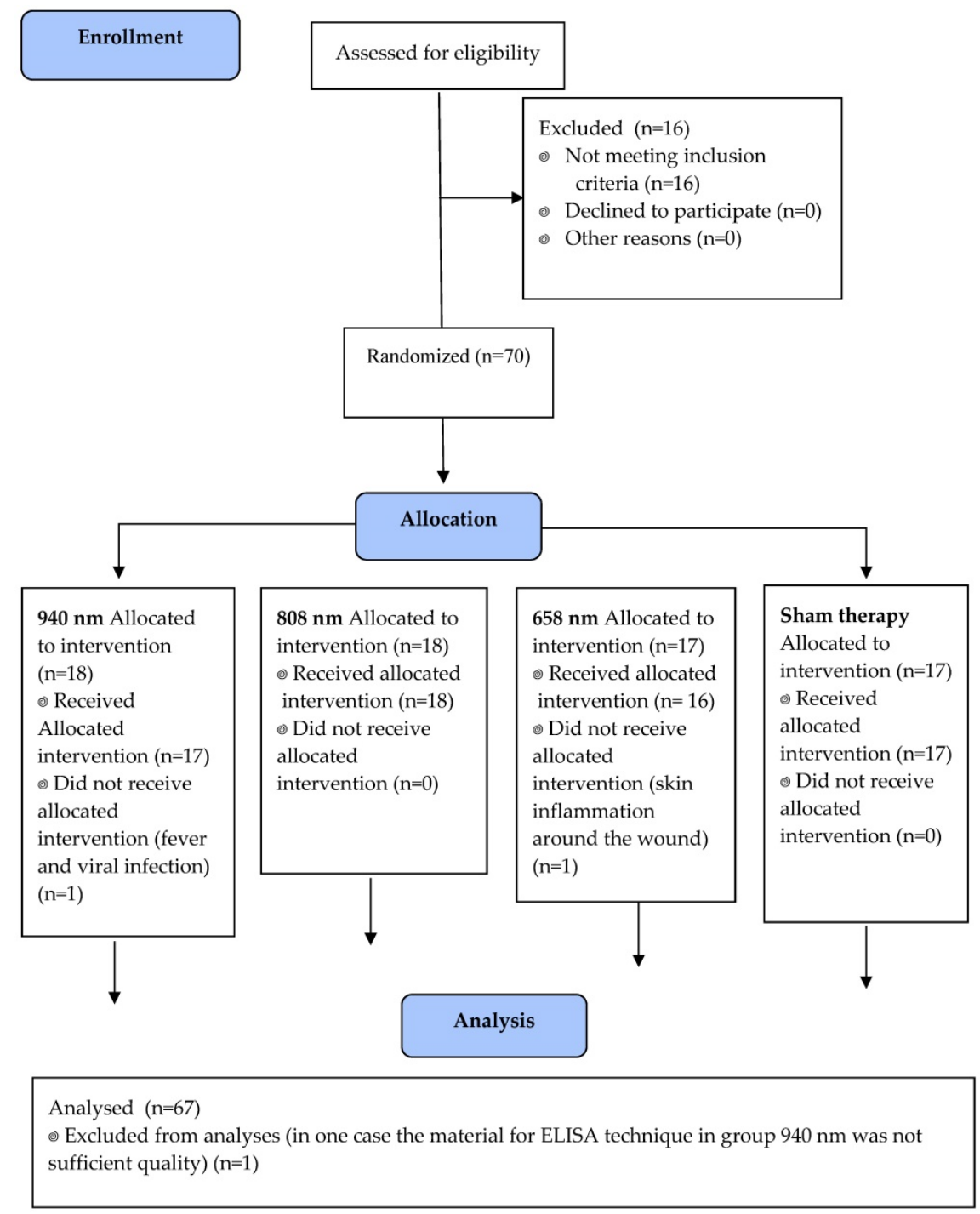

Figure 1. The CONSORT flow chart

confirmed by wound swab and bacteriological examination, foul odor, increased pain and inflammation in the tissue around the ulcer, lympho-flow and significant serous effusion), (2) use of drugs, such as corticosteroids, anticoagulants, opiates, antibiotics (3) use of special active dressings such as hydrocolloids, hydrogels, alginate, with the addition of metallic silver or any other type of therapeutic procedures different from those planned and used in this study, (4) non-compliance with ulcer management recommendations, (5) pregnancy, (6) ankle-brachial pressure index (ABPI) < 0.8, (7) diabetes (HbA1C > 7\%), (8) systemic sclerosis, collagenases, psoriasis and other autoimmune diseases, (9) neoplastic disease, (10) allergic reactions (11) diagnosed mental illness, alcoholism or other addictions.

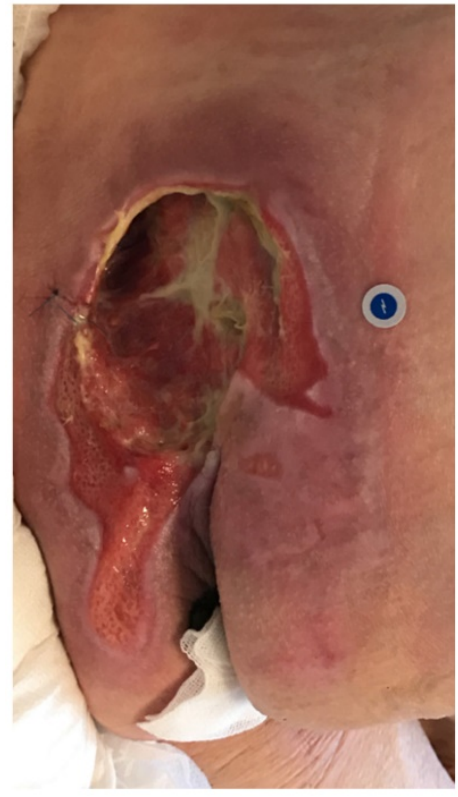

Figure 2. Ulcer in sacrum area 
All patients had a stabilized and unified diet one month before the start of the study and their nutritional status was monitored using the Nutritional Risk Screening Tool (NRS 2002) [15]. Nutritional supplementation was used when necessary to ensure that the patients received the recommended quantity of proteins, vitamins, and minerals. To determine whether patients met the criteria described in the protocol and whether there has been a deterioration of health status (some exclusion criteria could appear during the study), they underwent tests including standard blood morphology with smear, immunoassays, HbA1c, cholesterol level, hepatic enzymes, urinalysis and renal hemodynamics, ECG) twice within three months before the experiment, and once during the study time. Blood samples were tested to screen patients for nutritional status markers and metabolic disorders, such as different types of anemia, thyroid dysfunction, impaired glycemic control, dehydration, protein deficit, and hypoalbuminemia. In this way, a homogeneous and representative population was ensured in the comparison groups. The flow of patients in the study at its subsequent stages is shown in Figure 1 and the analysis was performed on 67 patients in total.

\section{Randomization and Blinding}

Patients were randomly allocated to four groups with the use of sealed envelopes with special codes inside. An administration official who had no further contact with the patient during the treatment and did not know the therapeutic details drew the envelopes. The devices were coded only with symbols, all the treatment parameters were prepared before the start of the study and the settings were fixed, thus the therapists performing laser therapy did not know anything about the doses of irradiation. Periodic monitoring of the apparatus was conducted by technicians who were not involved in the study and after treatment hours. Patients did not receive any information about group allocation and they could not distinguish the type of therapy. The collection of blood and wound tissue samples from the wound was done by other personnel who carried coded material for further diagnostics and the laboratory workers were unaware of any study details. The results for statistical analysis were also coded. Only the project coordinator and co-workers were able to decode the data, however, these employees did not have any contact with patients and could not influence the final results of the study.

\section{Interventions}

Patients from all groups received a basic treatment, including repositioning and mobilization, air pressure mattress and bed support surfaces, wound cleansing ( $0.9 \%$ normal saline). Additionally, skin in the wound area was cleaned with solutions: 1 . (2-Propanolum 45\%; 1-Propanolum 10\%; 2-Biphenylol $0.2 \%$; hydrogen peroxide; purified water) and 2 . (ethanol 46\%; isopropyl alcohol 27\%; benzyl alcohol $1 \%$; hydrogen peroxide; purified water). Patients received also the compound topical cream on the ulcer area $(1 \mathrm{~g}$ contains $20 \mathrm{mg}$ allantoin and $50 \mathrm{mg}$ dexopanthenol as a $50 \%$ solution of panthenol in propylene glycol) with an outer layer of a wet dressing held in place by a medical-quality rubberized fabric. A dressing change was carried out 1-2 times a day, depending on local exudation.

Patients from all groups received laser therapy once a day, 5 times a week for 1 month. The EzLase 940 (Biolase Technology, USA) and Rainbow Drops with SIX Laser 658 TS probe (Cosmogamma Group, Indonesia) devices were used for the treatments. There are semiconductor lasers (GaAlAs) which emitted a continuous radiation emission at separate wavelengths of $940 \mathrm{~nm}$ (group A), $808 \mathrm{~nm}$ (group B) and $658 \mathrm{~nm}$ (group C). The size of the laser spot was $0.1 \mathrm{~cm}^{2}$ when scanning the ulcer surface with a cone-shaped applicator (compound movement with a frequency of $20 \mathrm{~Hz}$ along the ordinate axis and $0.5 \mathrm{~Hz}$ along the abscissa axis). The applicator was applied non-contact from a distance of $2 \mathrm{~cm}$ to the wound. The duration of a single protocol depended on the size of the wound, and the therapy was adjusted to obtain an average dose of $4 \mathrm{~J} / \mathrm{cm}^{2}$ (direct dose measured on the surface of the wound using the Mentor MA10 device, ITAM Inc., Poland). In group D (sham therapy), laser therapy was applied in the same manner, but the device was off during each session (only the applicator was switched on to scan pressure ulcers using none coherent red visible light).

\section{Measures}

A fasting venous blood sample from the upper limb (5 ml) was collected three times - in the morning on the day prior to the treatment (day zero), after 2 weeks of irradiation and the day after the monthly laser therapy. Blood serum was obtained in a standard manner by centrifugation.

In addition, tissue samples measuring $3 \times 3 \times 3$ $\mathrm{mm}$ were taken from the bottom of the wound from all patients at the same three timepoints, i.e. on day zero, after 14 days and finally after the completed therapy- 4 weeks later).

The collected tissue samples were immediately washed with cold $1 \mathrm{X}$ phosphate-buffered saline (PBS), then placed on ice and cut into smaller pieces and frozen immediately in liquid nitrogen and stored on ice for rapid homogenization. Samples for further 
testing were stored at $-80^{\circ} \mathrm{C}$. Samples were placed in a test tube with a cold radioimmunoprecipitation assay buffer (RIPA) - $600 \mu \mathrm{l}$ of buffer for $10 \mathrm{mg}$ of tissue - with dithiothreitol protease inhibitors (DTT, leupeptin and aprotinin). Homogenization and cell lysis were performed with the UP200St ultrasonic homogenizer (Hielscher-ultrasound technology, Germany) for $5 \mathrm{~min}$ in a cycle of 15 seconds of sonification and 10 seconds of rest at $180 \mathrm{~W}$ (keeping the tube on ice). After the homogenization process, the lysate was centrifuged for $20 \mathrm{~min}$ at $27,000 \mathrm{~g}$. The collected supernatant was prepared for further testing.

A quantitative sandwich ELISA enzyme-linked immunosorbent assay was used to determine the level of IL-6, IL-2 interleukins and TNF-a tumor necrosis factor and TGF $\beta 1$, VEGF growth factors in the serum and lysate of the collected tissues. The test was performed with the use of Hangzhou MultiSciences kits (China) and (R \& D Systems, USA) according to the manufacturers' protocols. Standard solutions (100 $\mu \mathrm{l}$ two-fold dilution), test samples diluted in buffer $(20 / 80 \mu \mathrm{l})$ and biotin-bound specific detection antibodies (1: 100, $50 \mu \mathrm{l}$ ) were added to wells of microplates coated with specific monoclonal antibodies. Binding of the present antigens by immobilized antibodies occurred during incubation (2 $\mathrm{h}$ at room temperature on a microplate shaker, 300 rpm). After rinsing with buffer, streptavidinhorseradish peroxidase (HRP) solution (100 $\mu \mathrm{l})$ was added to each well and incubated $45 \mathrm{~min}$ at room temperature on a microplate shaker. The color of the samples was obtained by adding tetramethylbenzidine (TMB) solution and incubating in the dark at room temperature for $10 \mathrm{~min}$. After obtaining the color, the reaction was terminated by washing with buffer. Optical density (OD) was measured in a microplate reader at wavelength of $450 \mathrm{~nm}$.

\section{Statistical Analysis}

Statistica 12 (StatSoft, Inc., USA) was used to perform statistical analysis. All the studied quantitative variables were compared with the use of the Shapiro-Wilk test to determine the type of distribution. The comparisons between groups were performed using the non-parametric Kruskal-Wallis ANOVA test with multiple comparisons. The Friedman ANOVA test with multiple comparisons was used to compare results within the groups. The level of $\mathrm{p} \leq 0.05$ was considered statistically significant. In calculating our sample size we have allowed for: criteria);
- the minimum statistically significant difference would be set at $15 \%$ of the baseline

According to type I error, probability $\mathrm{a}=0.05$ and test power 1-beta $=0.90$ the detection of differences between four groups required at least 15 patients in each group (total of 60 patients).

\section{Results}

\section{Participant demographics}

Eighty-six patients were assessed for eligibility, of which sixteen patients were excluded from the study due to not meeting the criteria for inclusion. Seventy patients were randomized and allocated to the one of the intervention arms, however, two of them did not receive allocated intervention and one was excluded from analyses. Finally, sixty-seven patients were recruited, treated, and analyzed (group A - $940 \mathrm{~nm}: 17$ patients; group B - $808 \mathrm{~nm}: 18$ patients; group C - $658 \mathrm{~nm}$ : 16 patients; group D - sham therapy: 17 patients). The flow chart for study selection is shown in Figure 1 and the demographic and clinical characteristics are shown in Table 1.

Table 1. Baseline demographic characteristics of patients in groups.

\begin{tabular}{|c|c|c|c|c|}
\hline Characteristics & $\begin{array}{l}940 \mathrm{~nm} \\
(\mathrm{n}=18)\end{array}$ & $\begin{array}{l}808 \mathrm{~nm} \\
(\mathrm{n}=18)\end{array}$ & $\begin{array}{l}658 \mathrm{~nm} \\
(\mathrm{n}=17)\end{array}$ & $\begin{array}{l}\text { Sham therapy } \\
(n=17)\end{array}$ \\
\hline \multicolumn{5}{|l|}{ Gender [n (\%)] } \\
\hline Female & $12(66.66)$ & $11(61.11)$ & $11(64.70)$ & $11(64.70)$ \\
\hline Male & $6(33.33)$ & $7(38.89)$ & $6(35.30)$ & $6(35.30)$ \\
\hline \multicolumn{5}{|l|}{ Age [years] } \\
\hline Average (SD) & $\begin{array}{l}72.55 \\
(9.21)\end{array}$ & $\begin{array}{l}74.35 \\
(10.11)\end{array}$ & $\begin{array}{l}75.30 \\
(10.23)\end{array}$ & $71.65(8.67)$ \\
\hline \multicolumn{5}{|l|}{ BMI [n (\%)] } \\
\hline $\mathrm{BMI}>30$ & $1(5.55)$ & $1(5.55)$ & $1(5.88)$ & $1(5.88)$ \\
\hline BMI $<19$ & $1(5.55)$ & $1(5.55)$ & $1(5.88)$ & $1(5.88)$ \\
\hline $\begin{array}{l}\text { Disability in changing the } \\
\text { position }[\mathrm{n}(\%)]\end{array}$ & $10(55.55)$ & $9(50.00)$ & $10(58.82)$ & $9(52.94)$ \\
\hline \multicolumn{5}{|l|}{ Additional diseases [n (\%)] } \\
\hline General atherosclerosis & $12(66.66)$ & $11(61.11)$ & $11(64.70)$ & $10(58.82)$ \\
\hline Diabetes $(\mathrm{HbA} 1 \mathrm{C}<7 \%)$ & $7(38.88)$ & $6(33.33)$ & 7 (41.17) & $6(35.30)$ \\
\hline Cerebral strokes & $5(27.77)$ & $6(33.33)$ & $5(29.41)$ & $4(23.52)$ \\
\hline Myocardial infarction history & $5(27.77)$ & $5(27.77)$ & $5(29.41)$ & $4(23.52)$ \\
\hline Multiple ulcers [n (\%)] & $5(27.77)$ & $4(22.22)$ & $4(23.52)$ & $5(29.41)$ \\
\hline \multicolumn{5}{|l|}{ Wound area $\left[\mathrm{cm}^{2}\right]$} \\
\hline Average (SD) & $\begin{array}{l}32.44 \\
(16.33)\end{array}$ & $\begin{array}{l}29.11 \\
(12.89)\end{array}$ & $\begin{array}{l}35.76 \\
(15.23)\end{array}$ & 30.28 (12.77) \\
\hline \multicolumn{5}{|l|}{ Duration of ulcers [months] } \\
\hline Average (SD) & $\begin{array}{l}14.21 \\
(8.12)\end{array}$ & $\begin{array}{l}10.98 \\
(7.45)\end{array}$ & $\begin{array}{l}12.78 \\
(9.22)\end{array}$ & $16.02(11.56)$ \\
\hline \multicolumn{5}{|l|}{ EPUAP/NPUAP scale [n (\%)] } \\
\hline $\mathrm{II}^{\circ}$ & $5(27.77)$ & $6(33.33)$ & $6(35.30)$ & $5(29.41)$ \\
\hline $\mathrm{III}^{\circ}$ & $10(55.55)$ & $9(50.00)$ & $8(47.05)$ & $10(58.82)$ \\
\hline $\mathrm{IV}^{\circ}$ & $3(16.67)$ & $3(16.67)$ & $3(17.65)$ & $2(11.77)$ \\
\hline \multicolumn{5}{|l|}{ Ulcer placement [n (\%)] } \\
\hline Sacrum bone & $12(66.66)$ & $11(61.11)$ & $10(58.82)$ & $9(52.94)$ \\
\hline Ischial tuberosity & $3(16.67)$ & $4(22.22)$ & $4(23.52)$ & $5(29.41)$ \\
\hline Trochanter major & $3(16.67)$ & $3(16.67)$ & $3(17.65)$ & $3(17.65)$ \\
\hline
\end{tabular}

\section{Serum}

Immediately, the same day after the treatment it was clearly observed there was the greatest reduction 
in the concentration of pro-inflammatory interleukins in the blood in group C $(658 \mathrm{~nm})$. The significant change in these pro-inflammatory mediator levels [interleukin 2 (IL-2) with $\mathrm{p}=0.008$ and interleukin 6 (IL-6) with $\mathrm{p}=0.016$ ] was noticed after two weeks of laser therapy. In the other groups, the inflammation was also reduced, but the process was not as marked as in group C. Similarly, in the case of tumor necrosis factor (TNF-a) concentration, where after two weeks of treatment with irradiation at a wavelength of 658 $\mathrm{nm}$, a rapid suppression was observed $(\mathrm{p}=0.001)$, whereas in the other groups, these results were much slower and not as obvious. Further, the analysis shows that there were no differences between groups A $(940 \mathrm{~nm}), \mathrm{B}(808 \mathrm{~nm})$ and D (sham therapy), which indicates that laser therapy at these wavelengths does not bring an effective anti-inflammatory effect. However, the results in group C (658 nm) were significantly better than those obtained in the others groups. Detailed results are presented in Tables 2-4.

Table 2. Serum levels of IL-2 before, in the middle and after treatment in the four groups $(\mathrm{pg} / \mathrm{ml})$.

\begin{tabular}{lllll}
\hline Group & $\begin{array}{l}\text { Before } \\
\text { [average (SD)] }\end{array}$ & $\begin{array}{l}\text { 2 wks [average } \\
\text { (SD)] }\end{array}$ & $\begin{array}{l}\text { After [average } \\
\text { (SD)] }\end{array}$ & "p-value \\
\hline $940 \mathrm{~nm}$ & $95.45(13.23)$ & $74.34(10.67)$ & $66.78(9.23)$ & $\mathbf{0 . 0 3 4}$ \\
$808 \mathrm{~nm}$ & $100.21(14.54)$ & $69.47(10.02)$ & $67.78(9.01)$ & $\mathbf{0 . 0 3 2}$ \\
$658 \mathrm{~nm}$ & $\mathbf{9 7 . 8 9 ( 1 3 . 4 2 )}$ & $\mathbf{3 5 . 6 6 ( 4 . 3 8 )}$ & $\mathbf{2 6 . 4 5 ( 4 . 7 8 )}$ & $\mathbf{0 . 0 0 8}$ \\
Sham therapy & $94.11(11.98)$ & $70.21(9.89)$ & $66.36(8.89)$ & $\mathbf{0 . 0 3 5}$ \\
${ }^{* *}$ p-value & $\mathrm{p}=0.351$ & $\mathbf{0 . 0 1 2}$ & $\mathbf{0 . 0 1 2}$ & \\
\hline
\end{tabular}

*Friedman ANOVA, level of significance (before vs. 2 wks vs. after)

${ }^{* * K r u s k a l-W a l l i s ~ A N O V A, ~ l e v e l ~ o f ~ s i g n i f i c a n c e ~(A ~ v s . ~ B ~ v s . ~ C ~ v s . ~ D ~ g r o u p) ~}$

Table 3. Serum levels of IL- 6 before, in the middle and after treatment in the four groups $(\mathrm{pg} / \mathrm{ml})$.

\begin{tabular}{lllll}
\hline Group & $\begin{array}{l}\text { Before } \\
\text { [average (SD)] }\end{array}$ & $\begin{array}{l}\text { 2 wks [average } \\
\text { (SD)] }\end{array}$ & $\begin{array}{l}\text { After [average } \\
\text { (SD)] }\end{array}$ & * p-value \\
\hline $940 \mathrm{~nm}$ & $32.12(3.56)$ & $24.11(2.99)$ & $22.46(2.18)$ & $\mathbf{0 . 0 4 2}$ \\
$808 \mathrm{~nm}$ & $33.10(3.59)$ & $24.79(3.12)$ & $23.02(3.02)$ & $\mathbf{0 . 0 4 2}$ \\
$658 \mathrm{~nm}$ & $\mathbf{3 2 . 5 5 ( 3 . 4 3 )}$ & $\mathbf{1 4 . 1 8}(\mathbf{1 . 7 8 )}$ & $\mathbf{1 1 . 3 7 ( \mathbf { 1 . 6 6 } )}$ & $\mathbf{0 . 0 1 6}$ \\
Sham therapy & $31.98(2.89)$ & $24.44(3.21)$ & $22.69(3.11)$ & $\mathbf{0 . 0 4 2}$ \\
${ }^{* *}$ p-value & p=0.411 & $\mathbf{0 . 0 2 8}$ & $\mathbf{0 . 0 2 6}$ & \\
\hline *Friedman ANOVA, level of significance (before vs. 2 wks vs. after) \\
**Kruskal-Wallis ANOVA, level of significance (A vs. B vs. C vs. D group)
\end{tabular}

Table 4. Serum levels of TNF- $\alpha$ before, in the middle and after treatment in the four groups $(\mathrm{ng} / \mathrm{ml})$.

\begin{tabular}{|c|c|c|c|c|}
\hline Group & $\begin{array}{l}\text { Before } \\
\text { [average (SD)] }\end{array}$ & $\begin{array}{l}2 \text { wks [average } \\
\text { (SD)] }\end{array}$ & $\begin{array}{l}\text { After [average } \\
\text { (SD)] }\end{array}$ & ${ }^{*}$ p-value \\
\hline $940 \mathrm{~nm}$ & $228.33(24.18)$ & $131.33(22.99)$ & $123.77(22.78)$ & 0.026 \\
\hline $808 \mathrm{~nm}$ & $230.02(24.59)$ & $128.09(23.12)$ & $122.32(23.23)$ & 0.024 \\
\hline $658 \mathrm{~nm}$ & $227.89(3.43)$ & 75.03 (16.78) & $63.08(15.66)$ & 0.001 \\
\hline Sham therapy & 227.35 (2.89) & $126.67(23.21)$ & $121.92(23.19)$ & 0.024 \\
\hline${ }^{* *}$ p-value & $\mathrm{p}=0.468$ & 0.018 & 0.021 & \\
\hline
\end{tabular}

*Friedman ANOVA, level of significance (before vs. 2 wks vs. after)

**Kruskal-Wallis ANOVA, level of significance (A vs. B vs. C vs. D group)

\section{Wound Tissue}

The positive changes in the measured serum parameters were associated with tumor necrosis factor activity within the wound area. Table 5 illustrates the TNF-a levels. In all comparison groups, a significant decrease in the concentration of this inflammatory mediator was observed $(\mathrm{p}=0.033$ for 904 $\mathrm{nm}$; $\mathrm{p}=0.033$ for $808 \mathrm{~nm}$; $\mathrm{p}=0.025$ for $658 \mathrm{~nm}$; and $\mathrm{p}=0.033$ for sham therapy). Interestingly, again in the case of group C (658 nm), the change in TNF-a concentration was most intensive ( $\approx 75 \%$ reduction), whereas the changes in other groups were not as obvious ( $\approx 50 \%$ reduction).

Table 5. Wound levels of TNF- $\alpha$ before, in the middle and after treatment in the four groups $(\mathrm{pg} / \mathrm{mg})$.

\begin{tabular}{lllll}
\hline Group & $\begin{array}{l}\text { Before } \\
\text { [average (SD)] }\end{array}$ & $\begin{array}{l}\text { 2 wks [average } \\
\text { (SD)] }\end{array}$ & $\begin{array}{l}\text { After [average } \\
\text { (SD)] }\end{array}$ & "p-value \\
\hline $940 \mathrm{~nm}$ & $890.21(657.33)$ & $512.44(463.21)$ & $479.11(389.99)$ & $\mathbf{0 . 0 3 3}$ \\
$808 \mathrm{~nm}$ & $901.12(743.19)$ & $548.31(476.10)$ & $465.01(379.22)$ & $\mathbf{0 . 0 3 3}$ \\
$658 \mathrm{~nm}$ & $\mathbf{8 9 3 . 6 7 ( 6 8 7 . 0 9 )}$ & $\mathbf{2 0 2 . 3 9 ( 1 6 9 . 1 2 )}$ & $\mathbf{1 8 7 . 8 8 ( 1 2 5 . 4 4 )}$ & $\mathbf{0 . 0 2 5}$ \\
Sham therapy & $889.44(685.17)$ & $549.88(478.36)$ & $480.16(333.89)$ & $\mathbf{0 . 0 3 3}$ \\
${ }^{* *}$ p-value & $\mathrm{p}=0.450$ & $\mathbf{0 . 0 3 1}$ & $\mathbf{0 . 0 2 9}$ & \\
\hline
\end{tabular}

*Friedman ANOVA, level of significance (before vs. 2 wks vs. after)

**Kruskal-Wallis ANOVA, level of significance (A vs. B vs. C vs. D group)

After irradiation (658 nm), the VEGF expression increased significantly within the first two weeks, and then it decreased and maintained a stable level (Table 6). In contrast, the TGF $\beta 1$ activity remained level, but always higher in comparison to other groups (Table 7).

Table 6. Wound levels of VEGF before, in the middle and after treatment in the four groups (pg/mg).

\begin{tabular}{|c|c|c|c|c|}
\hline Group & $\begin{array}{l}\text { Before } \\
\text { [average (SD)] }\end{array}$ & $\begin{array}{l}2 \text { wks [average } \\
\text { (SD)] }\end{array}$ & $\begin{array}{l}\text { After [average } \\
\text { (SD)] }\end{array}$ & ${ }^{*}$ p-value \\
\hline $940 \mathrm{~nm}$ & $302.35(212.54)$ & $371.40(300.73)$ & $311.21(303.56)$ & 0.044 \\
\hline $808 \mathrm{~nm}$ & $299.03(208.38)$ & 367.21 (301.89) & 300.76 (301.62) & 0.043 \\
\hline $658 \mathrm{~nm}$ & 289.27 (199.59) & $476.22(413.02)$ & 357.09 (304.19) & 0.030 \\
\hline Sham therapy & 300.67 (208.89) & 368.08 (289.19) & $299.82(334.63)$ & 0.044 \\
\hline${ }^{* *}$ p-value & $\mathrm{p}=0.480$ & 0.038 & 0.046 & \\
\hline
\end{tabular}

Table 7. Wound levels of TGF $\beta 1$ before, in the middle and after treatment in the four groups $(\mathrm{pg} / \mathrm{mg})$.

\begin{tabular}{lllll}
\hline Group & $\begin{array}{l}\text { Before } \\
\text { [average (SD)] }\end{array}$ & $\begin{array}{l}\text { 2 wks [average } \\
\text { (SD)] }\end{array}$ & $\begin{array}{l}\text { After [average } \\
\text { (SD)] }\end{array}$ & " p-value \\
\hline $940 \mathrm{~nm}$ & $121.15(87.21)$ & $138.27(110.86)$ & $129.39(112.21)$ & 0.202 \\
$808 \mathrm{~nm}$ & $125.04(76.11)$ & $142.07(123.01)$ & $137.10(121.89)$ & 0.215 \\
$658 \mathrm{~nm}$ & $\mathbf{1 2 3 . 2 2}(\mathbf{8 0 . 0 2})$ & $\mathbf{3 1 2 . 5 4 ( 2 2 8 . 3 5 )}$ & $\mathbf{3 0 6 . 2 1}(\mathbf{2 3 1 . 0 3})$ & $\mathbf{0 . 0 2 3}$ \\
Sham therapy & $117.72(91.21)$ & $130.88(121.20)$ & $131.02(131.01)$ & 0.219 \\
${ }^{* *}$ p-value & $\mathrm{p}=0.329$ & $\mathbf{0 . 0 1 2}$ & $\mathbf{0 . 0 1 2}$ & \\
\hline${ }^{*}$ Friedman ANOVA, level of significance (before vs. 2 wks vs. after) \\
${ }^{* *}$ Kruskal-Wallis ANOVA, level of significance (A vs. B vs. C vs. D group)
\end{tabular}

\section{Discussion}

The use of laser therapy in the treatment of hard-to-heal pressure ulcers still stimulates a lot of controversy. On the one hand, it is a simple and popular tool in everyday clinical practice, on the other hand, it the level of scientific evidence is extremely 
poor. Referring to the latest systematic review published in 2017 [9] on the use of laser therapy in patients with pressure ulcers, it can be clearly seen that there is a lack of reliable and well-done studies in this area. Machado et al. in their critical review of the literature found as many as 386 articles on this subject, but only four publications met the criteria for inclusion for further analysis. These four studies conclude that the greatest therapeutic effects are associated with radiation at a wavelength of $658 \mathrm{~nm}$.

This conclusion is in line with our own clinical experience and the results of the publication from 2013 [13], however, a desire to understand the mechanisms in the process of healing pressure ulcers healing with the use of laser therapy contributed to the planning and conducting this research. With respect to the results we obtained, it seems that the successful effect of wound healing after irradiation at wavelengths of $658 \mathrm{~nm}$ is associated with an anti-inflammatory effect, as well as stimulation of such phenomena as angiogenesis, proliferation or remodeling of tissues during the process of wound closure. This is indirectly indicated by changes in the activity of the cytokines and growth factors examined in this study.

The significant reduction in the concentration of interleukins in the blood in group C $(658 \mathrm{~nm})$ shows strong anti-inflammatory effect of laser radiation at a wavelength of $658 \mathrm{~nm}$ on the systemic level. Additionally, the rapid suppression of serum TNF-a level probably allows for a smooth transition from the inflammatory phase to wound proliferation. The positive changes of TNF- $\alpha$ activity in wound biopsies seem to reflect the elimination of the inflammatory reaction after two weeks of $658 \mathrm{~nm}$ irradiations and then stimulation of healing processes in the period of proliferation and remodeling of pressure ulcers. Besides, the VEGF expression increased significantly in group $\mathrm{C}$ within the first two weeks, which may be in our opinion an indicator of stimulation of angiogenesis, and then it decreased and maintained a stable level. The obtained results clearly show that the process of angiogenesis observed as changes in vascular endothelial growth factor activity (VEGF) and proliferation as changes in transforming growth factor beta 1 (TGF $\beta 1$ ) activity in wounds was the most intensive with radiation of $658 \mathrm{~nm}$. Interestingly, electromagnetic radiation at a slightly different wavelength, for example, 940 or $808 \mathrm{~nm}$, proved to be completely ineffective in stimulating these reactions in the wound, which also explains the poor clinical results and the lack of fast healing process of pressure ulcers when using these parameters.

Up until now there is no similar study in the field of pressure ulcer treatment in the literature, hence it is difficult to compare our results with other scientific reports. This study is the first such trial, which certainly adds to its unique innovativeness. To our knowledge, only one article on laser therapy of chronic wounds, but of a different etiology can be found in the literature [14].

Ruh et al [16] in the latest report from 2018, described the laser treatment applied for twelve days (one treatment per day) using a similar wavelength to ours $(660 \mathrm{~nm})$ on diabetic-grade III and IV wounds. Unfortunately, the study included only eight patients without a control or comparison group. The researchers used a dose of $2 \mathrm{~J} / \mathrm{cm}^{2}$ (in our study it was $4 \mathrm{~J} / \mathrm{cm}^{2}$ ). Wound samples were collected twice, before the start of irradiation and after a 12-day series of treatments. They also evaluated the activity of the pro-inflammatory mediator TNF-a and growth factors VEGF and TGF $\beta 1$. It was observed that the TNF- $\alpha$ level decreased and the observed growth factors increased their activity. These results completely coincide with our findings, but since the Brazilian researchers only performed the treatment for 12 days, (in our case, the treatment lasted a month), it is not known whether further measurements in subsequent healing phases would be consistent with ours.

Finally, it seems that the therapeutic basis in the effective healing of pressure ulcers is connected with laser irradiation at a wavelength of $658 \mathrm{~nm}$ and its influence on the inhibition of inflammatory processes in the wound and stimulation of angiogenesis and fibroblast proliferation. Laser therapy at wavelengths of 940 and $808 \mathrm{~nm}$ does not significantly affect the above-mentioned repair processes, which explains its low effectiveness in the treatment of pressure ulcers and contributes to the confusion when determining the effectiveness of laser therapy.

\section{Limitations of the Study}

Our study is a pilot report and we are continuing to enroll eligible patients to increase the number of patients. Notwithstanding this limitation, relate back to original study results and what this study has added. In further studies we should collect blood samples (for nutritional status markers) also before and after the experimental procedure and monitor hypoalbuminemia status especially. It is also recognized that only a few factors related to healing and inflammation have been analyzed. It is necessary to determine the involvement of other important factors in the treatment of pressure ulcers, for example, PDGF, FGF or EGF growth factors, as well as the extremely interesting activities of MMP-2 and MMP-9 metalloproteinases with respect to the tissue TIMP inhibitor; and COX-2 activity. It would be also 
helpful to analyze the NGF as an additional marker considering its angiogenesis stimulation by activating multiple pathways $[17,18]$. Besides, in further studies we would like consider to quantify the effects of laser therapy directly on tissue samples. Measuring on tissue homogenates the levels of GFs as well as of interleukins could reduce the bias associated to systemic diseases and associated, but not discovered, comorbidities. The limitation of our study is lack of follow up assessment too.

\section{Conclusions}

In the present study, we showed that the effective healing of pressure ulcers is connected with laser irradiation at a wavelength of $658 \mathrm{~nm}$. We believe that this effect is related to the inhibition of inflammatory processes in the wound and stimulation of angiogenesis and fibroblast proliferation at this specific radiation (based both on concentration of interleukins and TNF-a serum level and VEGF, TGF $\beta 1$, TNF- $\alpha$ activities in wound biopsies). Laser therapy at wavelengths of 940 and $808 \mathrm{~nm}$ does not significantly affect the above-mentioned repair processes, which explains its low effectiveness in the treatment of pressure ulcers.

\section{Acknowledgments}

This study was conducted under a research project funded by the Ministry of Science and Higher Education in Poland (ST.E020.16.053) and Polish Society of Lymphology (PTL/1/2015). The study was also supported by the European Pressure Ulcer Advisory Panel (EPUAP).

\section{Competing Interests}

The authors have declared that no competing interest exists.

\section{References}

1. Demarré L, Van Lancker A, Van Hecke A, et al. The cost of prevention and treatment of pressure ulcers: A systematic review. Int. J. Nurs. Stud. 2015; 52: 1754-74

2. Dreyfus J, Gayle J, Trueman P, et al. Assessment of Risk Factors Associated With Hospital-Acquired Pressure Injuries and Impact on Health Care Utilization and Cost Outcomes in US Hospitals. Am. J. Med. Qual. Off. 2017; 1062860617746741

3. Muszalik M, Dijkstra A, Kędziora-Kornatowska K, et al. Health and nursing problems of elderly patients related to bio-psycho-social need deficiencies and functional assessment. Arch. Gerontol. Geriatr. 2012; 55: 190-4

4. Polak A, Kloth LC, Blaszczak E, et al. The Efficacy of Pressure Ulcer Treatment With Cathodal and Cathodal-Anodal High-Voltage Monophasic Pulsed Current: A Prospective, Randomized, Controlled Clinical Trial. Phys. Ther. 2017; 97: 777-89

5. Polak A, Kloth LC, Blaszczak E, et al. Evaluation of the Healing Progress of Pressure Ulcers Treated with Cathodal High-Voltage Monophasic Pulsed Current: Results of a Prospective, Double-blind, Randomized Clinical Trial. Adv. Skin Wound Care 2016; 29: 447-59

6. Dymarek R, Halski T, Ptaszkowski K, et al. Extracorporeal shock wave therapy as an adjunct wound treatment: a systematic review of the literature. Ostomy. Wound Manage. 2014; 60: 26-39

7. Von Felbert V, Schumann H, Mercer J, et al. Therapy of chronic wounds with water-filtered infrared-A (wIRA). GMS Krankenhaushygiene Interdiszip. 2008; 2: Doc52.
8. Chen C, Hou WH, Chan ESY, et al. Phototherapy for treating pressure ulcers. Cochrane Database Syst. Rev. 2014; CD009224

9. Machado RS, Viana S, Sbruzzi G. Low-level laser therapy in the treatment of pressure ulcers: systematic review. Lasers Med. Sci. 2017; 32: 937-44

10. Ebid AA, El-Kafy EMA, Alayat MSM. Effect of pulsed Nd:YAG laser in the treatment of neuropathic foot ulcers in children with spina bifida: a randomized controlled study. Photomed. Laser Surg. 2013; 31: 565-70

11. Moskvin SV, Geynitz AV, Askhadulin EV. Efficiency of a New Combined Laser Therapy in Patients With Trophic Ulcers of Lower Extremities and Chronic Venous Insufficiency. J. Lasers Med. Sci. 2017; 8, 132-5

12. National Pressure Ulcer Advisory Panel; European Pressure Ulcer Advisory Panel; Pan Pacific Pressure Injury Alliance In Prevention and Treatment of Pressure Ulcers: Quick Reference Guide; Haesler, E., Ed.; Cambridge Media: Perth, Australia, 2014

13. Taradaj J, Halski T, Kucharzewski M, et al. Effect of Laser Irradiation at Different Wavelengths $(940,808$, and $658 \mathrm{~nm}$ ) on Pressure Ulcer Healing: Results from a Clinical Study. Evid.-Based Complement. Altern. Med. 2013; 960240

14. Schulz KF, Altman DG, Moher D. CONSORT Group CONSORT 2010 statement: updated guidelines for reporting parallel group randomised trials. BMJ 2010; 340: c332

15. Rabito EI, Marcadenti A, da Silva Fink J, et al. Nutritional Risk Screening 2002, Short Nutritional Assessment Questionnaire, Malnutrition Screening Tool, and Malnutrition Universal Screening Tool Are Good Predictors of Nutrition Risk in an Emergency Service. Nutr. Clin. Pract. Off. Publ. Am. Soc. Parenter. Enter. Nutr. 2017; 32: 526-32

16. Ruh AC, Frigo L, Cavalcanti MFXB, et al. Laser photobiomodulation in pressure ulcer healing of human diabetic patients: gene expression analysis of inflammatory biochemical markers. Lasers Med. Sci. 2018; 33: 165-71

17. Micera A, Lambiase A, Stampachiacchiere B, et al. Nerve growth factor and tissue repair remodeling: trkA (NGFR) and p75 (NTR), two receptors one fate. Cytokine Growth Factor Rev. 2007; 18: 245-56

18. Zhao HT, Zhang YH, Zhang YH, et al. NGF/FAK signal pathway is implicated in angiogenesis after acute cerebral ischemia in rats. Neurosci Lett. 2018; in press 